\title{
La simulación como performance afectiva en los orígenes del feminismo
}

\author{
Cecilia Macón' (iD) 0000-0001-9195-021X \\ 'Universidad de Buenos Aires, Facultad de Filosofía y Letras, Buenos Aires, CABA, \\ Argentina. insfilo@filo.uba.ar
}

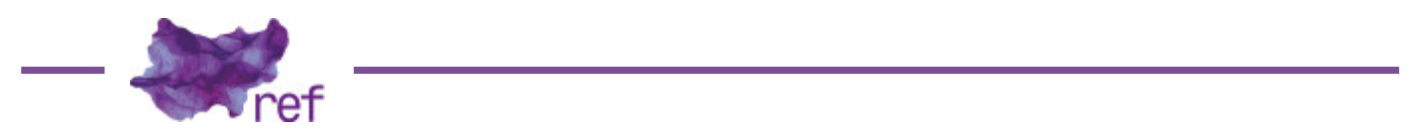

Resumen: Este artículo analiza el caso de los ensayos o simulación de votación por parte de las activistas por el voto femenino en tanto performances afectivas. Tomando centralmente como ejemplo los ensayos producidos en Argentina en marzo y noviembre de 1920, el objetivo central de esta presentación consiste en argumentar que la destrucción de la estructura del sentir patriarcal llevada a cabo por el feminismo altera el sentido de realidad a través de gestos propios de las vanguardias artísticas tal como estos actos de pre-enactment. Esta presentación argumenta que no se trató meramente de un cambio en el sentido del lenguaje emancipatorio en su relación con los afectos, sino que el orden performático de esos afectos ayudó a constituir una alteración del sentido de la realidad. Palabras clave: sufragismo; afectos; performance; simulacro.

\section{Simulação como atuação afetiva nas origens do feminismo}

Resumo: Este artigo analisa o caso dos ensaios ou simulações de votação das ativistas pelo voto feminino como performances afetivas. Tomando como exemplo central os ensaios produzidos na Argentina em março e novembro de 1920, o principal objetivo desta apresentação é argumentar que a destruição da estrutura de sentimentos patriarcais realizada pelo feminismo altera o senso de realidade através de gestos próprios da vanguarda artística como esses atos de pre-enactment. Esta apresentação argumenta que não foi apenas uma mudança no sentido da linguagem emancipatória em sua relação com os afetos, mas que a ordem performativa desses afetos ajudou a constituir uma alteração do sentido da realidade.

Palavras chave: sufrágio; afetos; performance; simulação.

Simulation as Affective Performance in the Origins of Feminism

Abstract: This article scrutinizes the mocking elections conducted by suffragists in terms of affective performances. Through the analysis of the simulations carried out in Argentina in March and November 1920, I claim that the demolition of the patriarchal structure of feelings executed by feminism altered the understanding of reality through gestures typical of the artistic avant-gardes such as these acts of preenactment. Indeed, this article argues that such performances incarnated both a shift in the emancipatory language as linked to affect and -most importantly -, due to the performative order of such affect, an alteration of the understanding of reality.

Keywords: Suffragism; Affect; Performance; Simulacrum.

\section{Introducción}

El 7 de marzo de 1920, alrededor de 5.000 mujeres votaron en las elecciones legislativas de la Argentina. Y lo hicieron sin la habilitación masculina. El 21 de noviembre de ese mismo año la acción se repitió en el marco de elecciones municipales. En un contexto de lucha por el sufragio -que fue legislado en el país recién en 1947-, distintas agrupaciones consensuaron intervenir el espacio público, convocando a participar de un simulacro o ensayo de votación a todas las mujeres, usando las listas disponibles en mesas de votación dispuestas en los lugares más diversos -ateneos políticos, organizaciones sociales, sociedad de socorros mutuos, cines, etc.-. Si en las 
elecciones masculinas triunfó la Unión Cívica Radical, en las femeninas -que, obviamente, no fueron contabilizadas de ningún modo- ganó por una diferencia abrumadora la lista socialista. Se trató de un acontecimiento con antecedentes internacionales, pero que logró en esa fecha concreta una visibilidad inédita, sacando a la luz una lucha colectiva que, entre otras cosas, se sostuvo siempre en la utilización de instrumentos de denuncia disruptivos -basta recordar, por ejemplo, la muerte de Emily Davidson tras irrumpir con su protesta en medio de la carrera del Derby en 1913. En el caso que nos ocupa, se trató de encarar la invasión del espacio político -de cuyas decisiones las mujeres se encontraban excluidas- a través de un acto de simulación, es decir, de una impugnación radical de aquello que es considerado real.

El objetivo central de este trabajo no es realizar una reconstrucción pormenorizada de ese evento o de sus antecedentes, sino analizar el caso en términos del modo en que esta suerte de performance invadió el espacio público expresando una estrategia de protesta que aquí denomino pre-enactment - o pre-creación-: un tipo de performance sostenida en una lógica donde queda expresado el modo en que los movimientos de mujeres, ya desde sus orígenes, buscaron exitosamente destruir una estructura del sentir patriarcal fijada en el abismo abierto entre la racionalidad masculina y la sentimentalidad femenina. 'Aquí, es el cuerpo el que se pone literalmente en juego al imponer una demanda que disuelve esta matriz. La dicotomía establecida por tal estructura del sentir patriarcal implica que las mujeres no solo no son racionales, sino que además sostienen gran parte de sus decisiones en una sentimentalidad descorporizada (Cecilia MACON, 2017). Por su parte, la imposición de los cuerpos presentes en los ensayos de votación enlazando presente con futuro de manera encarnada no solo señala el poder de una dimensión afectiva clave como es la visceralidad-algo así como la contracara de la sentimentalidad-, sino que además se muestra capaz de constituir ese mismo futuro de manera radical. Recordemos que el sentimentalismo desencarnado y, justamente por ello, desagenciado es el que predomina en las descripciones clásicas de la dicotomía patriarcal sostenidas en la tensión razón/emoción (Raia PROKHOVNIK, 1999; MACON, 2007). La sentimentalidad es, después de todo, una suerte de tecnología regulatoria (Kyla SCHULLER, 2017) tendiente a insistir en un solo aspecto de los afectos: el de ser estrictamente afectado, dejando así a un lado el vector correspondiente a la capacidad de afectar-según la clásica definición spinoziana que retoma el giro afectivo contemporáneo. ${ }^{2}$ Implica hacer foco en cierta debilidad (SCHULLER, 2017) sostenida en la sensibilidad más que en la agencia y en la necesidad de disolver los impulsos propios de las sensaciones (Dana LUCIANO, 2007). Como veremos a continuación, el tipo de operación que literalmente encarnan como performances los ensayos de votación, pone en primer plano el orden de lo visceral a la hora de construir una temporalidad que se pretende también constitución de lo real. La demolición de la dicotomía patriarcal resulta así, como veremos a través del análisis que propone este artículo, punto de partida para impugnar el modo en que se genera una concepción de posibilidad política sostenida en la opresión femenina.

Entiendo aquí que los ensayos o simulaciones de votación constituyen entonces una de las maneras más eficaces de jaquear esa estructura del sentir: la performatividad de los afectos literalmente puesta en escena a través de un gesto estético-político que intenta impugnar aquello que se entiende por real. Si el orden emocional femenino establecido por el patriarcado fue utilizado para recluir a las mujeres en un espacio privado asociado a la sentimentalidad, en nuestro ejemplo se trata de visibilizar esta operación opresiva a través de una puesta en escena que destruye un modo patriarcal de pensar los afectos al tiempo que derrumba su sentido de la realidad asociado a la exclusión de las mujeres de la política. El deseo de futuro es literalmente puesto en el presente, generando un real impensado. Y es, como veremos, el orden performático de esos afectos, aquello que ayuda a constituir una alteración del sentido de la realidad al estilo del trauma, pero con consecuencias empoderadoras, gracias a su orientación a cierto futuro.

Recordemos además que, tal como ha sido apuntado por Leslie Hill (2018), el sufragismo puede ser considerado el movimiento político que inventó la performance en tanto gesto artísticopolítico. Sea a través de desfiles con puesta en escena propia (Susan WARE, 2019) o de la irrupción en eventos patriarcales como las carreras de caballos, las sufragistas inventaron estrategias de

\footnotetext{
' Por "estructura del sentir" nos referimos al ya clásico concepto desplegado por Raymond Williams (1977) para dar cuenta de la matriz emocional de la experiencia histórica de una época, estructuras que actúan en tensión, desplazamiento y latencia con la cultura dominante.

El llamado "giro afectivo", en tanto tradición filosófica abierta hacia fines de la década del '90, intenta desplegar una perspectiva sobre el papel de los afectos en lo público cuestionadora de esquemas establecidos sobre el tema. De acuerdo a la caracterización propuesta por el giro, los afectos están vinculados a la labilidad, la contingencia y la sutileza constituyéndose también en articuladores de experiencia. Las emociones, en este marco, son sociales: no se trata de estados psicológicos, sino de prácticas sociales y culturales capaces de producir la superficie y los límites que permiten que lo individual y lo social sea limitado. Sociales, inestables, dinámicos, paradójicos, los afectos así presentados constituyen una lógica capaz de dar cuenta del lazo social. Se trata también de conceptualizar la capacidad para afectar y ser afectado, o el aumento y disminución de la disposición del cuerpo para actuar, enlazar y conectar. Efectivamente, lo que el giro afectivo ha discutido es que la presencia de los afectos implica una disolución de la distinción entre un polo activo y otro pasivo: el sufrimiento no implica ya pasividad; el trauma no resulta ya en el exclusivo ensimismamiento del ego.
} 
intervención destinadas no solo a visibilizar el reclamo, sino también a impugnar modos de hacer política sostenidos en un orden de lo afectivo destinado a la exclusión de las mujeres.

De hecho, si tomamos una fecha específica es porque particularmente el ensayo de ese 7 de marzo de 1920 es el que recibió más atención por parte de la prensa, pero también debido a que es del que queda mayor registro fotográfico. Fue justamente el acto mismo de tomar y hacer circular imágenes de mujeres encarnando el acto de votar uno de los efectos más buscados por parte de la estrategia de la simulación. Es que esas fotos puestas a circular en los periódicos y las revistas más difundidas de la época volvieron real aquello que el Estado patriarcal les negaba: la posibilidad de intervenir en política como electoras. Las imágenes capturadas ese día son, de algún modo, el registro de ese pre-enactment, y consiguen parte de su eficacia en su circulación poniendo en primer plano cuerpos agrupados para intervenir políticamente.

Nuestro trabajo intentará demostrar estas lecturas a través de tres momentos:

a) la reconstrucción del acto mismo de 1920 y de sus registros en el marco de la lucha por el sufragio;

b) el análisis en términos de performance de este tipo de protesta;

c) una reflexión sobre el pre-enactment en tanto estrategia de intervención política.

\section{El sufragismo organizado}

Hay una frase que la escritora norteamericana Joan Didion reproduce insistentemente a través de las páginas de Noches azules, el libro sobre la muerte impensada de su hija a los 39 años: "esto no debería estar sucediendo". No por repetida, esta oración simple y devastadora a la vez no deja de dar cuenta de las características fundamentales del trauma: su capacidad para alterar el sentido de la realidad. Los límites entre el orden de lo ficcional y lo real quedan aquí en un estado de ambigüedad suspendida en el tiempo. La discusión que me interesa plantear aquí está vinculada al rol político de una operación exactamente inversa a la del trauma: la proclamación, también insistente, de "esto debería estar sucediendo".

Creo que el desafío políico de esta frase como modo de pensar y ejecutar la emancipación da cuenta de manera acabada del caso que voy a presentar aquí, y resulta capaz además de abrir el debate alrededor de una cuestión que considero capital: discutir el potencial crítico de la idea de pre-enactment-o pre-creación- en el caso de la simulación de actos grupales de sufragio por parte de activistas por el voto femenino entre fines del siglo XIX y principios del XX. No se trataba en estos casos de votar avanzando sobre las grietas del sistema-como la conocida imagen de Julieta Lanteri votando en Buenos Aires el 26 de noviembre de 1911 tras una disputa judicial-, sino de la simulación pura, como la que quedó cristalizada en imágenes tomadas también en Estados Unidos y España. En este sentido resultó notable la intensa circulación de muchas de estas imágenes en las redes en el marco del llamado "activismo feminista hashtag" de los últimos dos años \#HuelgaDeMujeres, \#QueSeaLey, etc.-, en particular de la correspondiente a la simulación realizada en la Argentina en marzo de 1920. Este rescate por parte de los movimientos actuales de actos que hasta hace poco tiempo eran solo material de archivo para historiadoras profesionales no solo les ha otorgado una visibilidad notable, sino que además ha sacado a la luz la especificidad de este tipo de intervención pública.

El objetivo central de este artículo consiste en argumentar que la destrucción de la estructura del sentir patriarcal llevada a cabo por el feminismo -especialmente en esta primera ola- no solo conforma la agencia política de un modo particularmente disruptivo -y por ello, exitoso en el mediano y largo plazo-, sino que además altera el sentido de realidad a través de gestos propios de las vanguardias estéticas a través de operaciones como estas que aquí denomino "pre-enactments", cercanas de algún modo al "fake" del movimiento beat, donde la categoría de "fake" expresó "la invención de hechos falsos para crear acontecimientos verdaderos" tal como la falsa celebración de los yppies en 1967 del fin de la Guerra de Vietnam encabezados por Allan Ginsberg (Guiomar ROVIRA, 2016, p.101). Es en este sentido que Ewa Ziarek (2008) ha señalado que los reclamos de las feministas constituyen un ejercicio del derecho a la rebelión -más que a la revolución- que implicó un uso radical del discurso. Recordemos en este sentido que, de acuerdo con la clásica distinción de Christopher Hill la rebelión, fuertemente asociada a la lógica de la desobediencia civil - a través de su conocida fórmula "el mundo patas arriba" (Cristopher HILL, 1984) - supone el despliegue de la ira para imponer un matriz sacrílega. Así, en los términos de Ziarek (2008), la táctica en un punto irónica ejecutada en los reclamos sufragistas buscaba alterar radicalmente el sentido de las palabras, señalando y ejecutando el costado creativo de la práctica política. Se trataba además de una estrategia donde el lenguaje sobre los afectos -tanto los denominados positivos como los negativos- cumplía un rol central. Para evocar esto basta no solo recordar que el documento correspondiente al primer encuentro del feminismo -antes de que existiera el término- se llamó Declaración de 
sentimientos (1848), ${ }^{3}$ sino además que una de las frases insignia de Emmeline Pankhurst pronunciada en uno de los momentos más violentos de la lucha en 1913 fue: "Nosotras conocemos la alegría de una batalla" (Emmeline PANKHURST, 2018, p.144). Intentaremos argumentar aquí que a la hora de interpretar el movimiento feminista en sus orígenes es necesario ir aún más lejos. Es decir, que no se trató meramente de un cambio en el sentido del lenguaje emancipatorio en su relación con los afectos, sino que el orden performático de esos afectos alteró el sentido de la realidad tal como lo hace el trauma, aunque con consecuencia divergentes gracias a su orientación al futuro. Es así como en el caso de los ensayos de votación de las sufragistas, la constitución de una realidad alternativa, más que el proyecto de un nuevo comienzo asociado tradicionalmente a los movimientos revolucionarios, se ajusta a un estado de sacrilegio que no busca asumirse como interpretación, sino, en tal caso, como la imposición de lo oculto que es, además, lo debido.

Es importante señalar que el uso de los simulacros de votación formó parte de los mecanismos de protesta de los grupos de sufragistas más radicales. Así, por ejemplo, en Estados Unidos fue Harriot Stanton Blatch y su Equality League of Self-Supporting Women quien, en 1907, ejecutó esta forma de intervención pública. Miembro del Partido Socialista de Estados Unidos y de la Sociedad Fabiana británica, fuertemente influida por Emmeline Pankhurst y consciente también de la necesidad de impulsar un movimiento de mujeres obreras (Ellen DUBOIS, 1997), Blatch fue quien introdujo las estrategias destinadas a invadir el espacio público a través de acciones espectaculares y teatrales al sufragismo norteamericano (DUBOIS, 1997). A partir de allí, muchos de los simulacros se realizaron en universidades femeninas desde donde se hacía una importante difusión del hecho a través de periódicos locales y universitarios.

Aún cuando en los inicios del movimiento en la Argentina no hubo acuerdo sobre las estrategias a desplegar -por ejemplo, la socialista Alicia Moreau comenzó siendo partidaria de un esquema escalonado- ${ }^{4}$, lo cierto es que rápidamente las distintas tácticas se enlazaron para unificar los modos de activismo. Las visitas de Belén de Sárraga a la Argentina -breves en 1906 y en 1910 para participar respectivamente del XIII Congreso Internacional de Libre Pensamiento y del Congreso Internacional Femenino, pero extendida entre 1915 y 1921 - también cumplieron un papel clave no solo en términos de una activación directa, sino también por el modo en que sus viajes por la región colaboraron en poner en contacto los colectivos sufragistas de los distintos países. Pero es sin dudas el rol cumplido por el Partido Socialista en la internacionalización del reclamo y de las estrategias aquello que resultó fundamental. Si en 1910 se realiza el Primer Congreso Femenino en Buenos Aires, $1919^{5}$ es la fecha clave del activismo sufragista local. ${ }^{6}$ Es en ese año -mientras se habilita sufragio femenino en el Reino Unido y un año antes de que se incorpore en Costa Rica y de que se apruebe la Enmienda XIX que permitió el voto de las mujeres en Estados Unidos - cuando se redacta el primer proyecto de sufragio femenino en Argentina firmado por el diputado radical Rogelio Araya. Es en 1919 también cuando Miguel J. Font realiza una encuesta a personalidades sobre el feminismo, a partir de la cual escribe un libro en defensa del sufragio femenino llamado Encuesta Feminista Argentina. 1919 es, además el año en que Julieta Lanteri encabeza el primer acto callejero protagonizado por mujeres (Araceli BELLOTTA, 2001). Y es justamente en las elecciones de ese 7 de marzo de 1920 cuando la propia Lanteri se presenta como candidata por el Partido Feminista Nacional.

De hecho, es a lo largo de los años '20, década abierta por los simulacros que nos ocupan, cuando el movimiento gana en masividad contando, incluso, con cierto apoyo de sectores de la

\footnotetext{
${ }^{3}$ La presentación de la citada declaración en términos de "sentiments" requiere de una aclaración. A lo largo del siglo XIX la noción de "sentiment" fue utilizada frecuentemente en el ámbito del debate público como camino para expresar una toma de posición u opinión. De hecho, el documento fundador de la American Anti-Slavery Society presentado en 1833 y escrito centralmente por William Garrison fue la Declaration of Sentiments of the American AntiSlavery Society y en 1850 se promulga en Boston la Declaration of Sentiments of Coloured Citizens. De acuerdo con el Diccionario Webster publicado en Nueva York en 1828 "sentiment" es, además de emoción, afecto o sentimiento, "un pensamiento impulsado por una pasión o sentimiento". Es también, se señala, un concepto que implica la expresión de una opinión formada por la "deliberación". No se trataba por cierto de la única palabra disponible para dar cuenta de la toma de posición de la reunión. Su elección implicaba hacerse cargo del papel de los sentimientos -que en el mismo diccionario refiere también en tanto emociones o afectos- en la lucha política- a la hora de definir deseos o fantasías políticas en términos de la expresión de sentimientos o deseos de de derechos.

${ }^{4}$ La primera publicación autodeclarada feminista de la Argentina fue organizada por María Abella Ramírez en 1901 y se denominó Nosotras. Años más tarde, en 1909, en otra publicación que dio continuidad a Nosotras, denominada La Nueva mujer, se desarrollaron posiciones más incisivas en materia de voto femenino.

${ }^{5}$ Es importante recordar que fue en 1912 cuando se proclamó la llamada Ley Saenz Peña, destinada a asegurar el voto masculino universal, secreto y obligatorio.

${ }^{6}$ Esto no implica ignorar las acciones previas del movimiento. La Voz de la Mujer fue el primer periódico feminista anarquista redactado por mujeres de la Argentina, publicado en Buenos Aires entre 1896 y 1897 y en Rosario en 1899. En 1900 Cecilia Grierson, al volver del Segundo Congreso Internacional de Mujeres celebrado en Londres en 1899, establece el Consejo Nacional de Mujeres en Argentina. En 1902 las hermanas Fenia y Mariana Chertkoff fundan el Centro Feminista Socialista. En 1903 se funda la Unión Gremial Feminista, en 1904, la Asociación de Universitarias Argentinas, en 1906, la Liga Argentina de Mujeres Librepensadoras, y en 1910 se realiza el Primer Congreso Femenino Internacional presidido por Grierson.
} 
Iglesia Católica. En 1920 se realiza el VIII Congreso Feminista Internacional con representación argentina en la figura de Brunhilda Wien y, en 1922, la Primera Conferencia Panamericana de Mujeres en Baltimore. El primer triunfo local llega en 1928, cuando la provincia de San Juan habilita a votar a las mujeres en las elecciones provinciales de ese año.

Así, el momento en que se activa el desarrollo de las estrategias de simulación de votación en Argentina dista de ser casual, tanto en términos de sus antecedentes, como de los efectos generados. El activismo sufragista local tuvo así un primer desarrollo en los años posteriores a la Primera Guerra Mundial -momento, tal como señalamos, en que el voto femenino comienza a ser una realidad en algunos países (Dora BARRANCOS, 2014)-, y logra visibilidad a partir de la fecha que nos ocupa. En el desarrollo de la estrategia local tuvo sin dudas un papel preponderante el Partido Socialista, pero también lo tuvieron movimientos alejados de las estructuras partidarias y tan diversos como la masonería, el krausismo y la tradición higienista-en este caso como modo de luchar contra el alcoholismo masculino (BARRANCOS, 2005)- o incluso ciertos sectores católicos (BARRANCOS, 2014). A nivel internacional, en 1892 el Partido Socialista en el Congreso celebrado en Erfurt decidió impulsar el derecho al voto de las mujeres (BARRANCOS, 2005) inaugurando el compromiso de cada una de las estructuras partidarias a nivel local. El ejemplo de la socialista Alicia Moreau es en este sentido paradigmático. A su regreso del Congreso Internacional de Libre Pensamiento, en 1907, funda, convencida por la causa, el Comité Pro-Sufragio Femenino. En 1919 toma contacto con feministas norteamericanas en el Congreso Internacional de Obreras realizado en Washington, donde participaron 200 mujeres de diecinueve países para discutir el rol de las mujeres proletarias. Un año más tarde funda la Unión Feminista Nacional que, junto al Partido Feminista Nacional establecido por Julieta Lanteri en 1918 y la Asociación Pro-Derechos de la Mujer de Elvira Rawson y Alfonsina Storni -en actividad desde 1919-, impulsan y ejecutan los ensayos de votación de 1920: el primero, durante las elecciones legislativas del 7 de marzo, y el segundo el 21 de noviembre, en el marco de elecciones municipales (BARRANCOS, 2005). En palabras de Moreau se trataba de "despertar la atención de las mujeres, interesarlas en el movimiento, provocar una manifestación de opiniones" (BARRANCOS, 2005, p. 172), pero también de recordar que este tipo de acciones directas son las destinadas a ser las más exitosas a la hora de conseguir objetivos que rechazan la narrativa de la espera por tratarse de una mera estrategia de dilación. Dice Moreau al respecto: "la huelga de hambre-mejor diríamos de los hambrientos ha mostrado cómo la acción colectiva obtiene en poco tiempo, lo que escapa a cualquier otro medio de acción" (NUESTRA CAUSA, n.24, p. 278).

Estas simulaciones abren, sin dudas entonces, una década clave donde, a través de argumentos sostenidos en las leyes inglesa y norteamericana, se logra votar en la provincial de San Juan, y donde el uso de ciertas estrategias de intervención sacan a la luz marcas del feminismo anglosajón - John Stuart Mill y la Declaración de sentimientos de Seneca Falls aparecen referidos insistentemente-, pero también experiencias de la primera posguerra, del movimiento español y de la Revolución Rusa, así como estrategias propias que serán recogidas por otros activismos, en especial, justamente, el español.

La constitución de una red internacional potente con sentidos de circulación múltiples a través de lecturas, la presencia de visitantes internacionales, la participación activa en eventos transregionales, la multiplicación de delegadas y corresponsales de las organizaciones locales en distintos países -como Herminia Galindo en México, Brunhilda Wieu en Austria, Ignacio Gorelik (el único varón), en Estados Unidos o Dora Meyer ${ }^{7}$ en Perú- permite evitar pensar los modos de intervención elegidos en tanto meras reproducciones de las estrategias impulsadas en el norte. ${ }^{8}$

No es casual que con el apoyo del Partido Socialista local -que incorporó la cuestión a su plataforma-, del Partido Feminista y de ciertos sectores de la Unión Cívica Radical se haya desplegado la acción que nos ocupa en marzo de 1920, interviniendo las elecciones legislativas destinadas a renovar 102 de los 158 diputados existentes en nueve provincias y en la Capital Federal. El ensayo de voto femenino de ese día fue promovido y llevado adelante por un grupo de organizaciones feministas integradas, entre otras, por la escritora Alfonsina Storni, las socialistas Julieta Lanteri y Alicia Moreau -presidenta de la Unión Feminista Nacional- y la radical Elvira Rawson de Dellepiane. Con apoyos y rechazos de ideologías varias -basta notar, por ejemplo, que uno de los ensayos más publicitados se realizó en un local de la Liga Patriótica gracias al vínculo de ciertos sectores del radicalismo con esta organización nacionalista-, el hecho logró impacto más allá de sus adherentes. Al respecto basta señalar, por ejemplo, que el 8 de marzo el periódico El Diario, bajo el título de "Inocente diversión electoral", describe el ensayo en términos de apatía, fraude, juego, mentira,

\footnotetext{
${ }^{7}$ El impulso por conformar un movimiento transregional resulta transparente al constatar no solo la cantidad de embajadoras del activismo argentino en otros países, sino también por el importante espacio dedicado en las publicaciones a reproducir extensas notas de la prensa feminista internacional.

${ }^{8}$ Es importante apuntar sin embargo que, tal como ha señalado Allison Sneider (2008), el movimiento sufragista norteamericano puede ser leído como una instancia imperialista más, ya que son numerosas las referencias a la necesidad de intervenir en áreas del mundo atravesadas por la "barbarie". Sin embargo, la circulación en términos de estrategias y argumentos distó en los hechos de ser biunívoca.
} 
cansancio y poco convencimiento, a lo que suma la siguiente descripción: "entraron dos jovencitas al parecer estudiantes, aún sin experiencia de la vida y menos sabedoras de las necesidades de un país, que de los respectivo a los encantos de su edad y sexo; después entraron dos o tres mujeres al parecer obreras; de estas hubo más número que de las otras" (EL DIARIO, 8/3/1920, p. 11). Diversidad social y etaria destinada a describir un supuesto ámbito de ignorancia en el marco de un mero juego que asocia mujer con infancia a la espera de protección. Sin embargo, no toda la prensa masiva se opuso. La revista Caras y Caretas, por ejemplo, apoyó el acto con ciertos reparos clasistas: el sufragio debía limitarse a las mujeres educadas.

El papel de la publicación feminista socialista Nuestra causa (NC), fundada justamente en 1919, fue en este sentido clave para la difusión del activismo de esos años y de esta intervención en particular. Bajo la dirección de Julia García Games, a lo largo de cada uno de sus números pueden rastrearse, tanto sus exigencias fundamentales -los derechos civiles y políticos, pero también, por ejemplo, una demanda de reescritura de la historia desde el punto de vista de la mujer-, como también el debate acerca de las acciones concretas a tomar. Justamente, el simulacro, ensayo o "parodia" -tal como lo denomina el diario socialista La Vanguardia (1920) al respaldar la convocatoria de votación- fue promovido desde las páginas de NUESTRA CAUSA, en febrero de 1920, bajo el siguiente argumento:

No habrá verdadera democracia mientras la "Mujer" no tenga derechos políticos y civiles en condiciones iguales al hombre (...) ¿Para qué quieren el voto las mujeres? Para luchar más eficazmente contra el analfabetismo, el alcoholismo, la prostitución y el vicio. Para contribuir activamente al mejoramiento social. Para apoyar eficazmente sus reivindicaciones y conseguir su emancipación económica y social. (NUESTRA CAUSA, n. 10, p. 232)

A este argumento se suma una advertencia clave explicitada en un editorial junio de 1921: "no solo es ésta una aspiración sentimental, sino una necesidad imperiosa, impostergable, de todo punto de vista apremiante: queremos votar" (NUESTRA CAUSA, n. 24, p. 272). Como se señala en el número 11 de NUESTRA CAUSA, se trataba de demostrar "la profundidad del deseo de votar" (NUESTRA CAUSA, n. 11, p.32). Es así como el deseo en tanto impulso a un tiempo que es el ahora, y no el futuro lejano en el horizonte de la narrativa del progreso, es el que define la intervención que nos ocupa. Alejadas explícitamente de la sentimentalidad que, tal como se señaló más arriba, les fue adjudicada por el patriarcado a la hora de legitimar su opresión, se opta por la intervención movida por el deseo de la transformación radical y urgente de lo público. Hay aquí una justificación de las intervenciones en las elecciones masculinas de 1920 que explicita la exigencia de la emancipación de las mujeres como una necesidad imperiosa e inmediata que debe hacer a un lado cualquier pretensión propia de la moderación de la sentimentalidad. Es así, un deseo visceral que compromete el cuerpo de las mujeres -en la difusión y en la acción misma-, aquello que moviliza al colectivo a intervenir un acto patriarcal con reglas y puesta en escena propias. Se trata entonces de poner en acto aquello que debería estar sucediendo.

Los performances de marzo y noviembre de 1920 fueron promovidas, además de a través de las clásicas conferencias públicas de ateneos políticos, mediante pegatinas en las calles llevadas a cabo exclusivamente por mujeres, y festivales de música, literatura y cine con programación propia desplegados de manera estratégicas desde un mes antes de las votaciones. Es decir, que se trató de una movilización que, desde su difusión, apeló a mecanismos no tradicionales. Se trataba, en las palabras de sus impulsoras, de organizarse, "destruyendo prejuicios ancestrales, librándose de la cadena oxidada del dogma y el atavismo que la encerraba en el círculo de esclavitud, como prueba del progreso del feminismo en nuestro país" (NUESTRA CAUSA, n. 1 1, p. 34). El acto del 7 de marzo, se dice en el número siguiente al ensayo, "logró despertar a un gran número de mujeres que, por tradición o egoísmo del hombre, se hallaban en el letargo, en cuanto a sus derechos se refiere" (NUESTRA CAUSA, n.11, p. 244). Tras 24 días de propaganda previos en los que grupos de mujeres se ocuparon de empapelar la ciudad de Buenos Aires con su promoción, se apuntó en las páginas de NC: "todas unidas por el sentimiento de la urgencia de ser reconocidas como seres humanos trabajamos incesantemente" (NUESTRA CAUSA, n. 11, p. 245).

Ese 7 de marzo votaron en la ciudad de Buenos Aires -un distrito donde se encontraban empadronados 161.441 varones- alrededor de 4.000 mujeres en casi 30 mesas dispuestas para tal fin. Y lo hicieron, nuevamente según sus propias palabras, "para destruir mitos pero también para educar" (NUESTRA CAUSA, No. 24, p. 23). Tal como se señaló en un artículo central publicado por Julia García Games días antes, "pedir el voto como algo inmediato" (NUESTRA CAUSA, No.21, p. 13) tenía como objetivo central sacar a la luz la injusticia, pero también irrumpir en el espacio público a través de acciones radicalmente disruptivas al obligar a entender -y a encarnar en un acto- que acontecimientos como el sufragio femenino deberían estar sucediendo.

\section{El pre-enactment como modo de intervención}

Es importante señalar a esta altura de nuestro trabajo que a lo largo de la discusión sobre el sufragio universal desplegada fundamentalmente a partir del siglo XIX-y sus resultados escalonados- 
no se prohibió explícitamente que las mujeres votaran. Simplemente nadie lo imaginaba posible. Era entonces ese orden imaginario el que resultaba imperioso alterar a través de las performances de simulación. Gran parte de las intervenciones contra la implementación del sufragio femenino se produjeron bajo una matriz sostenida en el ridículo, la sátira y hasta el absurdo -basta recordar en este sentido las innumerables caricaturas destinadas a objetar la intervención en política de las mujeres o de actos específicos como los desfiles a caballo (WARE, 2019)-: la mera posibilidad de imaginar mujeres votando se tornaba intolerable para el orden patriarcal; la de las mismas mujeres burlando un acto protagonizado por varones, tal vez aún más. De hecho, uno de los rasgos centrales del gesto del pre-enactment de los ensayos de votación consistió justamente en resignificar las pretensiones de tildar la acción como ridícula o absurda al encarnar el acto mismo. Si el ridículo es, en la clásica definición de Aristóteles, aquello que está fuera del tiempo y del espacio, ponerlo en escena en el espacio público derrumba por sí mismo esa misma pretensión. Es más, una observación detallada de muchas de las fotos hace posible identificar un gesto irónico y desafiante en varias de las protagonistas -nunca hay solemnidad en el armado de las situaciones ni en los gestos-. Basta en este sentido notar que la foto que más circuló (Imagen 1) en el marco del activismo feminista hashtag de los últimos años muestra a un grupo de mujeres encabezadas por Rawson -en un local del grupo nacionalista Liga Patriótica Argentina- mirando fijamente a cámara. Quien está emitiendo su voto por primera vez es claramente la mujer más joven. Hay un listado de votantes siendo completado paso a paso por parte de dos activistas y un total de ocho mujeres a cargo de la organización en esa sede. La foto -como la gran mayoría de las de la época- es claramente posada, pero hay más convencimiento que ironía en la composición.

Casi como si el acontecimiento fuera enteramente real y estrictamente rutinario.

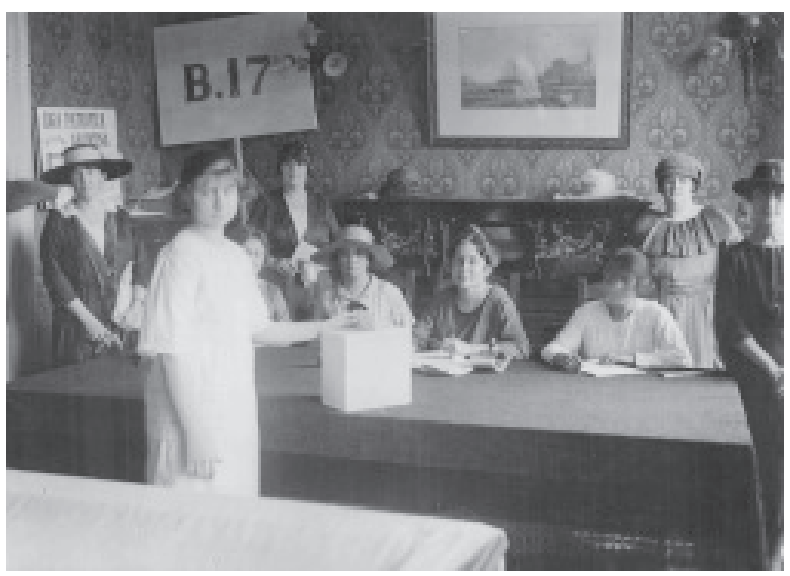

Imagen 1. Fuente: Archivo General de la Nación. Documento fotográfico Caja 200 , inv. 7856.

\#PraTodoMundoVer: Ocho mujeres sufragistas, seis de ellas con sombreros de distinto tamaño, supervisan un ensayo de votación en la sede de la Liga Patriótica Argentina en Buenos Aires en 1920 mientras otra mujer joven vestida de blanco introduce un sobre con su votación en la caja electoral también blanca. Todas están mirando a la cámara. Detrás del escritorio donde se constituye la mesa electoral se observa sobre una pared entelada el cuadro de un paisaje y a hacia la izquierda de la imagen una pancarta blanca que reza "B.17". A la izquierda de la imagen sobre una pared perpendicular a la que hace de fondo se observa, sostenido sobre una biblioteca baja, un cartel de la Liga Patriótica Argentina.

Imagen 2. Fuente: Archivo General de la Nación. Documento fotográfico Caja 1022, inv. 142555.

\#PraTodoMundoVer: En Mendoza, Argentina, (1920) una mujer joven votando vestida de blanco y con sombrero de paja, tres sufragistas sentadas detrás de una mesa de madera con sombreros de tela, controlando la votación en una caja electoral blanca colocada en una mesa de madera, y otras tres sufragistas, vestidas también de blanco, paradas en el fondo. Las tres miran a la cámara y una de ellas ríe. A la izquierda de la imagen y detrás de la votante se observan tres afiches pegados de manera irregular sobre una pared de madera.

La segunda foto (Imagem 2) fue tomada ese mismo día en la provincia de Mendoza y se sostiene en una composición no tan posada y con menos miradas a cámara. El grupo de tres mujeres vestidas estratégicamente de blanco que se ubican en un segundo plano, detrás de la votante -también joven- son las encargas de algún modo de comentar la situación que están viviendo. Hay, aquí sí, una superposición de naturalidad,

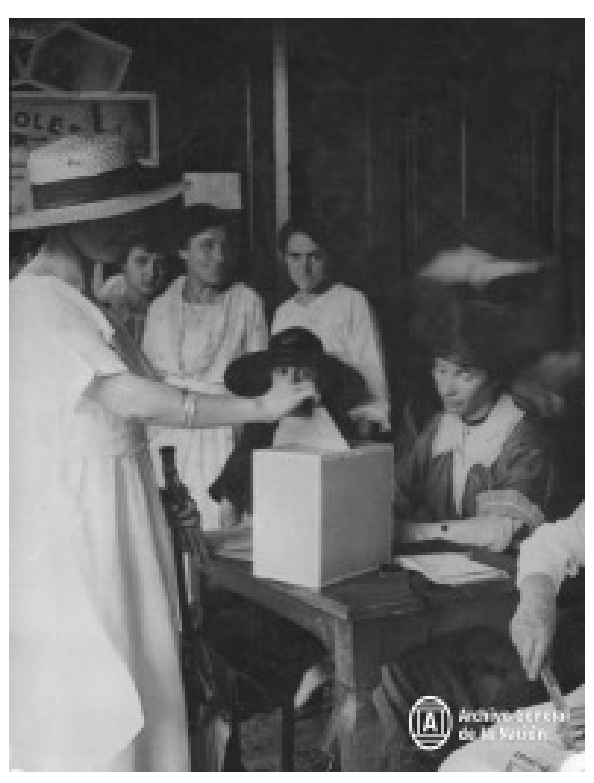
ironía y desafío en estas tres miradas que subrayan una situación presentada de manera dinámica -alguien saca punta a un lápiz mientras se registra el acto y la votante vestida de blanco mira fijo 
una urna que es exactamente igual a la de la sede de Buenos Aires. ${ }^{9}$ Siendo que la acción de miles de mujeres votando se realizó repitiendo cada uno de los pasos burocráticos del ritual del voto masculino -autoridades, padrón, urnas, boletas de la elección de ese día-, una nueva realidad comenzó a imponerse. Nos enfrentamos así a un intento por sostener esta situación supuestamente absurda del voto de quienes están impedidas de hacerlo poniéndola en escena, y de este modo devolver el mote de ridículos y poco realistas a los propios detractores. En una inversión clave, el objeto de esta suerte de sátira pasa así a ser la actitud de quienes lo prohíben. Como el uso del ridículo ejecutado por las vanguardias (el Teatro de lo ridículo, Tristan Zara, los happenings) hay aquí un intento por devolver en espejo la falta de sentido de la realidad hacia los propios objetores. Después de todo, el acto-aunque incompleto en sus efectos- se produjo. Es inevitable aquí recordar que en uno de sus discursos más citados Elizabeth Cady Stanton -una de las fundadoras del movimiento sufragista en Seneca Falls y madre de Helen Stanton Blatch- se ocupó explícitamente de reivindicar el uso del ridículo como mecanismo de protesta. En un discurso de 1894, afirmó: "Hablan de lucha. A mí me parece que aquellas que han sufrido persecución, ridículo y lágrimas han encarado la mejor lucha. No tenemos miedo al ridículo, porque el ridículo es lo que difunde el conocimiento de la verdad. Ridículo, ridículo, ridículo, Dios bendiga el ridículo" (DUBOIS, 1997, p. 106). Haber hecho el ridículo no es más, dice, que una forma de legitimación de la propia lucha, como lo son el sufrimiento y la persecución. ${ }^{10}$ Es a partir de allí que se difundió la estrategia de los simulacros. En 1917 las sufragistas norteamericanas gestaron una votación paralela en las mismas sedes de las elecciones nacionales con urnas propias donde se convocaba a votar a los hombres sobre su conformidad - o no - con el sufragio femenino. Un objetivo similar tuvo la postulación de Julieta Lanteri por el Partido Feminista también a las elecciones del 7 de marzo de1920: demostrar que había hombres decididos a apoyar el voto femenino. ${ }^{11}$

Podemos pensar entonces esta operación de simulacro en tanto un gesto estético profundamente vanguardista llevado a cabo por el primer feminismo. Recordemos que las vanguardias -de acuerdo a la reconstrucción conceptual desarrollada por Arthur Danto (2003), por ejemplo- suponen una pretensión de encarnar la verdadera naturaleza del arte en detrimento de la que exhiben sus rivales estéticos. No solo decían algo diferente sobre el arte, sino que expresaban su realidad definitiva. En el caso del feminismo se trató de reclamar que el movimiento encarnaba una realidad más ajustada y justa de lo público, y no meramente de una interpretación alternativa. La simulación saca a la luz la injusticia que nadie quiere ver o la opresión que nadie imagina, logrando así alterar la temporalidad acercando, tal como reclamaron las propias organizadoras de los simulacros en sus convocatorias, el futuro al presente de manera urgente movidas por el deseo más visceral.

Me parece relevante recordar aquí que se torna importante visualizar la historia del feminismo como una operación que busca objetar el modo en que se construyó emocionalmente la legitimación de los mecanismos opresivos, y no como una estrategia meramente refractaria decidida a deslegitimar el rol de lo afectivo en la política. Al respecto, basta recordar las ya clásicas reconstrucciones llevadas a cabo por Raia Prokhovnik en Rational Woman (1999) y por Susan Mendus en Feminism and Emotion (2000), donde se da cuenta de la lucha política por romper la dicotomía patriarcal entre mujer y razón y hacer a un lado el argumento de la opresión de género sostenido en la supuesta emocionalidad o sentimentalidad femenina.

Recordemos además que, en términos de Joan Wallach Scott:

una historia feminista que toma por seguros la inevitabilidad del progreso, la autonomía de los agentes individuales y la necesidad de elegir entre igualdad y diferencia reproduce sin cuestionarlos los términos del discurso ideológico dentro del cual ha operado. (SCOT, 1996, p. 2)

Es decir, que la historia de los orígenes del feminismo debe ser encarada evitando patrones establecidos como el del progreso en la historia del propio movimiento, pero también introduciendo variables generalmente no tenidas en cuenta para la reconstrucción del modo en que fue cuestionada la noción patriarcal de ciudadanía, como el deseo y la urgencia alegados por las organizadoras de los simulacros de 1920. Es necesario entonces encaminarse-como intentamos

\footnotetext{
${ }^{9}$ El uso del color blanco fue incorporado al movimiento sufragista hacia la segunda década del siglo XX por razones estratégicas consistentes con los ejes de este trabajo. En su desarrollo de tácticas visuales el colectivo advirtió que, siendo que las fotos tomadas eran en blanco y negro, el color blanco se destacaba mucho más que otras tonalidades y hacía más llamativas las acciones, en particular en su contraste con las vestimentas oscuras de los hombres que solían observar las intervenciones callejeras. Se trataba también de mostrar la pureza y el honor vinculados a su reclamo y de apelar a un color que, por su bajo costo, resultaba accesible a todas las clases sociales.

${ }^{10}$ En este sentido es clave recordar que, por ejemplo, la primera procesión organizada por la NUWSS (National Union of Women's Suffrage Societies) en Londres fue la «Mud March" (Marcha del Barro), celebrada en febrero de 1907. Ese día más de 3.000 mujeres marcharon desde Hyde Park a Exeter Hall para abogar por el sufragio femenino. La circulación de imágenes de activistas embarradas de piés a cabeza desafió cualquier prejucio previo y dejó en claro que el ridículo no era un límite para el movimiento.

11 Otro de los desafíos que se produjeron bajo esta estrategia consistió en presentar fiscales mujeres para las elecciones protagonizadas por varones. (DUBOIS, 1997).
} 
hacer acá- hacia una reconstrucción que busque estrategias distintas a las de las perspectivas historiográficas establecidas. Es allí donde la acción política es pensada y ejecutada bajo matrices diferentes: burlando lo real y haciendo de la presencia de los cuerpos parte clave de esa impugnación al orden dado.

Entiendo que lo que intentó hacer el feminismo asociado al sufragismo a través de gestos vanguardistas como el citado es atender a la llamada esfera visceral (Elizabeth WILSON, 2015) a la hora de exigir ser reconocidas como ciudadanas, buscando alterar el sentido de realidad. De hecho, tal como he comentado más arriba, se ha señalado insistente y acertadamente que el feminismo fue el movimiento que inventó la performance (HILL, 2018) como gesto artístico-político poniendo en jaque, como toda intervención performática, la lógica misma de la representación y los modos establecidos del debate público (Rebecca SCHNEIDER, 2011) a través de una carnadura de la acción que pone en primer plano el rol de la visceralidad en el arte. Las sufragistas fueron así las primeras en "organizar una estrategia artística en tanto una espada y un escudo políticos a una escala masiva, haciendo de la denuncia de la injusticia política una expresión de sus creencias en términos de 'un arte de la indignación en tu cara'” (HILL, 2018, p.151), claramente visceral.

Justamente, y en términos políticos, la idea de "visceralidad" (Sianne NGAI, 2015; WILSON, 2015) pone bajo nueva luz el rol de lo corporal y de la acción en la dimensión político afectiva. Sea a través de la rabia (WILSON, 2015), la inquietud o la melancolía, el amor o el odio, la visceralidad refiere a "Ia experiencia de sentimientos o respuestas afectivas altamente mediadas por el cuerpo que se manifiestan a través de reacciones emotivas y corporales" (Zeb TORTORICI, 2014 , p. 407). Se trata de una visceralidad que pone ciertamente en primer plano la dimensión corporal (WILSON, 2015), pero siempre bajo un rango de descripciones que obliga a pensar esa misma actitud visceral como modo de expresar/experimentar la política en términos de lo instintivo y de la alteración radical de lo tenido como dado.

Los escritos de Emmeline Pankhurst y de Olympe de Gouges o las campañas por la temperancia generadas sobre todo en Estados Unidos dan cuenta sin dudas de estas características. Al respecto es central recordar el análisis que Lynn Hunt despliega en relación al rol de la imaginación en la gestación de derechos femeninos en tanto "torrentes de emoción" (HUNT, 2010, p.25). Es esa línea de investigación la que se intenta esbozar aquí, señalando, no solo la potencia crítica del primer feminismo a la hora de analizar políticamente el rol de los afectos, sino su propuesta -condensada en esas simulaciones o ensayos- de exceder esa esfera para señalar y ejecutar una realidad alternativa. Como señala Joan Scott $(1999$, p. 3) en un análisis ya clásico sobre el concepto de "experiencia", no se trata meramente de "visibilizar" aquello que estaba oculto, sino también de mostrar la contingencia de lo que se asume como "dado". En nuestro caso, a través de un acto de simulación insistente que genera en sí mismo otra realidad.

\section{Simular para hacer}

En los ensayos de votación no nos enfrentamos a una puesta en escena paródica - en términos del oxímoron asociado a la ironía - como en el caso de los trabajos inaugurales de Judith Butler (1990) sino, como venimos argumentando en estas páginas, de un simulacro. Es inevitable evocar aquí los ya algo olvidados desarrollos de Jean Baudrillard (1978) que, sin embargo, resultan necesarios al utilizar este vocabulario. Recordemos que, en sus términos, la posmodernidad genera una hiperrealidad sostenida en el imperio del mapa y la desaparición del territorio donde una sucesión de simulacros supera la realidad y logra imponerse por sí misma. Según su definición canónica "la simulación no corresponde ni a un territorio, a una referencia, a una sustancia, sino que es la generación por los modelos de algo real sin origen ni realidad: lo hiperreal" (Jean BAUDRILLARD, 1978, p. 9). Es decir, que nos encontramos ante una operación donde se intenta hacer coincidir lo real con sus modelos de simulación (BAUDRILLARD, 1978), liquidando todos los referentes y negando al signo como valor. Se trata así de introducir la duda sobre lo real (BAUDRILLARD, 1978). Esta descripción que, para Baudrillard, permite dar cuenta de las causas de la manipulación de las masas en la era posmoderna podría ser utilizada para interpretar el fenómeno que nos ocupa de manera exactamente inversa. Es decir, que la liquidación de los referentes puede habilitar la generación de otros nuevos y no meramente someter a las masas a la manipulación, sino tal cumplir un papel en la emancipación. "La simulación" - dice el filósofo francés- "permite suponer (...) que el orden y la ley mismos podrían muy bien no ser otra cosa que simulación" (BAUDRILLARD, 1978, p. 47). Justamente, lo que las sufragistas buscaban encarnar a través de sus simulaciones o ensayos era que el orden, la ley y el referente debían ser jaqueados con el objetivo de establecer un orden más justo, orden que para el poder patriarcal era simplemente absurdo. La implosión del sentido (BAUDRILLARD, 1978) que Baudrillard vincula al repliegue de las masas sobre lo privado (BAUDRILLARD, 1978) en el marco del imperio de los medios masivos de comunicación adquiere aquí una fuerza asociada a la emancipación. Desde el análisis aquí encarado, entiendo entonces que esta misma definición usualmente utilizada para impugnar un modo de ser de lo 
público en la era posmoderna puede ser utilizada, no ya de manera nostálgica, sino como modo de iluminar una estrategia emancipatoria en términos de "pre-enactment" o "pre-creación".

Así como el "re-enactement" - o "re-creación"- fue descripto clásicamente por Robin George Collingwood (1996, p. 271) en términos de la recreación en la mente del historiador de los pensamiento de los actores de pasado, también ha sido puesto en juego posteriormente para dar cuenta de performances como las ejecutadas en museos o protestas callejeras destinadas a dar cuenta del pasado, no en términos de "re-presentación", sino de "presentación", es decir de su encarnación en el presente. En cualquiera de las dos acepciones supone ciertamente una fuerte puesta en juego de la imaginación. El enactement ejecutado en el caso que nos ocupa hace un uso insistente de la misma dimensión imaginativa y encarnada, pero orientándola hacia el futuro. Se "pre-crea" aquello que debería ser. Es el deseo de algo que fue considerado meramente posible, aquello que se encarna en los cuerpos de la protesta. Se trata de una suerte de flashforward que empasta afectivamente presente y futuro a través del desafío que esos cuerpos representan para la temporalidad lineal. Es más, tal como ha sido señalado, este tipo de intervención expresa un agenciamiento radical de quien lo produce (Adam CZIRAK et al., 2019); pocas cosas pueden agenciar más que señalar y ejecutar como real aquello que se considera imposible.

La noción de re-enactment contemporánea -heredera entonces de la presentación collingwoodiana- está inevitablemente asociada a la performance como modo de evocación del pasado en términos de un redo o replay dirigido a un evento precedente (SCHNEIDER, 2011). Junto a la llamada "historia viviente" que se produce en museos y parques temáticos, constituye un modo de, en términos de Dinshaw, "tocar el pasado; un tocar que no implica resurrección o recomposición" (Carolyn DINSHAW, 1999, p. 16), sino que exhibe la radical contingencia de quien toca y de quien es tocado. La performance es entonces estrictamente una re-performance de un evento pasado que se reproduce en el presente con el frecuente objetivo de curar el dolor (SCHNEIDER, 2011). En la repetición contenida del re-enactment los participantes luchan por mantener el pasado vivo (SCHNEIDER, 2011) y no por superarlo como lo harían bajo una lógica progresiva de la historia. Siendo que, tal como ha señalado Schneider, los "eventos históricos nunca están estrictamente terminados" (SCHNEIDER, 2011 , p. 33), porque el pasado permanece, se trata de un desafío a la temporalidad lineal (DINSHAW, 1999) que supone, además, un "salto de afectos" al estilo del señalado por Alphonso Lingis: es decir, el modo en que los "afectos saltan" entre los cuerpos, "cruzan los límites de los cuerpos, entrando y saliendo de esos cuerpos como si no hubiera fronteras entre ellos" (SCHNEIDER, 201 1, p.36). Pero, así como el pasado no se encuentra simplemente detrás de nosotros, el futuro no está tampoco simplemente delante (SCHNEIDER, 2011). Es decir, que la idea de pre-enactment-que, como la de re-enactment implica su propia cualidad efímera (SCHNEIDER, 201 1)- refiere de manera encarnada o "pre-performa" el futuro. Así como los tableaux vivants podían referir a eventos pasados o a situaciones que nunca sucedieron señalando una instancia de deseo (Hans BELTING, 1997), los simulacros de votación profundizan ese deseo hasta imponerlo como realidad inmediata. La conexión afectiva con el pasado, que es central en el caso del re-enactment, deviene clave también en su relación con el futuro en el caso del preenactment: se trata aquí de "tocar el futuro" y así materializarlo.

Por lo tanto, así como la performance en tanto recreación o reactualización supone un cuestionamiento a la temporalidad lineal, el pre-enactment en tanto "pre-creación" señala no solo la urgencia, sino también la exigencia de la superposición del futuro en el presente a partir de la puesta en primer plano de los cuerpos femeninos. En el marco de esta disolución de la matriz temporal progresiva, la dimensión afectiva conforma y es conformada por semejante alteración temporal. En términos de Dana Luciano: "Ias distinciones en el tiempo están completamente generadas por la experiencia temporal. De hecho, las pasiones son la estructura del tiempo al entrar en nuestras vidas; crean un paisaje temporal de otro modo homogéneo" (LUCIANO, 2007, p. 12). Pero a su vez - y nuevamente según Luciano- el despliegue del cuerpo que siente es index de una temporalidad que, cuando se aparta de la lineal progresiva, deviene una crononormatividad afectiva alterada (LUCIANO, 2007).

La puesta en escena de los simulacros de votación tenía como uno de sus objetivos centrales, tal como se señaló más arriba, la toma de una fotografía, en general sumamente posada, al margen de cualquier estrategia más o menos espontánea, pero donde se combinan ironía, desafío y hasta gestos que condensan la rutina de la burocracia que le otorgan realidad al acto. Realizadas en general dentro de instituciones, no invadían de manera directa el espacio público como los piquetes, las marchas, los discursos, los festivales, los desfiles, la rotura de vidrieras o las huelgas de hambre en plena calle, sino que se ejecutaban en un ámbito protegido para lograr la reproducción de las imágenes de las mujeres votando. Tal como señalé más arriba, era la circulación de la foto de un acto que estrictamente hablando no sucedió, pero que debería haber sucedido, aquello que estaba destinado a colaborar en la emancipación de las mujeres. Por cierto, estos actos tenían también una fuerte función pedagógica a nivel del saber práctico: aproximar a las mujeres al uso de boletas, padrones y urnas, una serie de elementos fatalmente 
alejados de su cotidianidad. Y es en esta instancia, de manera estratégica, que la operación retórica de la fotografía logró transformarse en un desplazamiento clave de los límites entre ficción y realidad; entre lo que es y lo que debería ser.

Interesa pensar estos ensayos de votación -que es como estrictamente los llamaron las sufragistas de 1920- en tanto gestos estéticos donde la rebelión muestra de manera prístina su naturaleza iconoclasta. De hecho, el vocabulario con el que se suelen describir estos actos en el ámbito anglosajón -donde, se señaló más arriba, fueron llevados a cabo por las ramas más radicales del movimiento como la liderada por Harriot Stanton Blatch- era el de mock voting,,$^{12}$ es decir, votación fingida o simulada, pero también burlada. Un rasgo que ayudó a que fueran descriptos por los movimientos anti-sufragistas como meros fraudes o mentiras.

La circulación de la refiguración del papel de las emociones en el agenciamiento político y la constitución de la ciudadanía para las mujeres implicó, así, no solo objetar la asociación de las mujeres con la sentimentalidad (Lauren BERLANT, 2008; SCHULLER, 2017) -tal como ha sido aquí señalado-, sino además exhibir a través de una estructura del sentir alternativa, una estructura de lo real también alternativa. Instalar de manera eficaz entonces una matriz donde los afectos encabalgados en el deseo de lo inmediato ingresan a lo público de manera explícita, reconfigurando la idea de ciudadanía femenina como un hecho.

Es allí entiendo donde se encuentra el corazón de la revulsión feminista, antes aún de que hubiera una autoconciencia expresada en esos términos: la vocación por demoler la estructura del sentir establecida por el orden patriarcal y la pretensión visceral de imponer su reemplazo por una estructura alternativa solo parecen posibles mediante la puesta en funcionamiento de la esfera afectiva expresada en términos no meramente de disputas hermenéuticas, sino de la imposición de una realidad alternativa. El "mundo puesto patas arriba" (Cristopher HILL, 1984) de su rebelión implicó sacar a la luz la naturaleza performática de lo visceral para hacer dudar a los interlocutores sobre su propio sentido de la realidad. Una visceralidad que se expresó en el acto mismo de ese día 7 de marzo, pero también en muchas de las palabras que se utilizaron para su difusión en términos de un llamado a la Resistencia, que es un acto tan radical como el retiro absoluto de la colaboración. "iResistir al pago leyes impositivas que no habían votado, resistir al fisco, a las autoridades, eso se llama tener buena conciencia del movimiento propio!" (NUESTRA CAUSA, n. 24, p. 273) se lanzó desde las páginas de la NC en 1921, al impulsar una lucha que suponía nuevas realidades para el fisco y para la idea misma de autoridad.

Se trató, entonces, más que de una construcción de la realidad, de una devastación de lo que se entendía como real: es decir, la opresión de las mujeres en tanto naturalizada. Así, la ejecución fue llevada a cabo alterando la estructura del sentir patriarcal en un nivel que excede el lenguaje sobre las emociones para develar su naturaleza performática y, por ello, tal vez volviendo al vocabulario de las primeras líneas-, traumática para los propios opresores.

\section{Referencias}

BARRANCOS, Dora. "Socialismo y sufragio femenino. Notas para su estrategia (1890-1947)". En: CAMARERO, Hernán; HERRERA, Carlos Miguel (eds.). El Partido Socialista en Argentina. Sociedad, política e ideas a través de un siglo. Buenos Aires: Prometeo, 2005, p. 159-184.

BARRANCOS, Dora. "Participación política y luchas por el sufragio femenino en Argentina (19001947). Cuadernos de Intercambio sobre Centroamérica y el Caribe, v. 11 , n. 1, p. 15-26, enerojunio 2014. http://hdl.handle.net/1 1336/3685.

BAUDRILLARD, Jean. Cultura y simulacro. Barcelona: Kairós, 1978.

BELLOTTA, Araceli. Julieta Lanteri. Buenos Aires: Galerna, 2001.

BELIING, Hans. Likeness and Presence: A History of the Image Before the Era of Art. Chicago: University of Chicago Press, 1997.

BERLANT, Lauren. The Female Complaint: The Unfinished Business of Sentimentality in American Culture. Durham: Duke University Press, 2008.

BUTLER, Judith. Gender Trouble. Nueva York: Routledge, 1990.

COLLINGWOOD, Robin George. Idea de la Historia. México: Fondo de Cultura Económica, 1996.

CZIRAK Adam et al. "P(reenactment)". En SLABY, Jan et. at. (eds.). Affective Societies. Londres: Routledge, 2019. p. 200-209.

12 En 1914 la Winnipeg Political Equality League creó incluso un "Mock Parliament" que parodió la negativa a incorporar la discusión en el ámbito parlamentario canadiense a través de una puesta en escena. 
DANTO, Arthur. Después del fin del arte. Buenos Aires: Paidós, 2003.

DINSHAW, Carolyn. Getting Medieval. Sexualities and Communities. Pre- and Postmod-ern. Durham: Duke University Press, 1999.

DUBOIS, Ellen. Harriot Stanton Blatch and the Wining of the American Suffrage. New Haven: Yale University Press, 1997.

HILL, Christopher. The World Turned Upside Down, Londres: Penguin, 1984.

HILL, Leslie. Sex, Suffrage and the Stage. Londres: Red Globe Press, 2018.

HUNT, Lynn. La invención de los derechos humanos. Barcelona: Tusquets, 2010.

LUCIANO, Dana. Arranging Grief: Sacred Time and the Body in Nineteenth-Century America. Nueva York: NYU Press, 2007.

MACON, Cecilia. "Ansiedad, indignación y felicidad para la emancipación: el camino de Mary Wollstonecraft". En: LOSIGGIO, Daniela; MACÓN, Cecilia (eds.). Afectos políticos. Buenos Aires: Miño y Dávila ediciones, 2017, p. 31-50.

MENDUS, Susan. Feminism and Emotion. Readings in Moral and Political Theory, Londres: MacMillan Press, 2000.

NGAI, Sianne. "Visceral Abstractions". GLQ A Journal of Lesbian and Gay Studies, v. 1, n. 4, p. 33-63, junio 2015. https://doi.org/10.1215/10642684-2818648.

PANKHURST, Emmeline. My Own Story. Londres: Musaicum Books, 2018.

PROKHOVNIK, Raia. Rational Woman. A Feminist Critique. Londres: Routledge, 1999.

SCHNEIDER, Rebecca. Performing Remains: Art and War in Times of Theatrical Reenactment. Londres: Taylor and Francis, 2011 . Edición Kindle.

SCOTT, Joan. "Experiencia”. Revista Hyparquia, v. X, n. 1, p. 72-89, diciembre1999.

SCOTT, Joan. Only Paradoxes to Offer. Cambridge: Harvard University Press, 1996.

SCHULLER, Kyla. The Biopolitcs of Feeling. Race, Sex and Science in the Nineteenth Century. Durham: Duke University Press, 2017.

SNEIDER, Allison. Suffragist in an Imperial Age. Oxford: Oxford University Press, 2008.

TORTORICl, Zeb. "Visceral Archives of the Body". En GLQ. Gay and Lesbian Studies, v. 20, n. 4, p. 407437, enero 2014. https://doi.org/10.1215/10642684-2721375.

WARE, Susan. Why They Marched. Untold Stories of the Women who Fought for the Right to Vote. Cambridge: Harvard University Press, 2019.

WILLIAMS, Raymond. "Estructura del sentir”. En: Marxismo y Literatura. Buenos Aires: Península, 1977. WILSON, Elizabeth. Gut Feminism. Durham: Duke University Press, 2015.

ZIAREK, Ewa Plonowska: "Right to Vote or Right to Revolt? Arendt and the British Suffrage Militancy". Differences: A Journal of Feminist Cultural Studies, v. 19, n. 3, p.1-27, julio 2008. https://doi.org/ 10.1215/10407391-2008-008.

Fuentes

EL DIARIO. Buenos Aires, 8 de marzo de 1920.

LA VANGUARDIA. Buenos Aires, 7 al 25 de marzo de 1920.

NUESTRA CAUSA. Buenos Aires, n. 10, febrero de 1920.

NUESTRA CAUSA. Buenos Aires, n. 11, abril de 1920.

NUESTRA CAUSA. Buenos Aires, n. 24, junio de 1921. 
Cecilia Macón (cmacon@yahoo.com) es docente e investigadora de la Facultad de Filosofía y Letras de la Universidad de Buenos Aires. Es licenciada y doctora en Filosofía por la misma universidad y MSc en Teoría Política por la LSE. Es autora del libro monográfico Sexual Violence in the Argentinean Crimes Agains Humanity Trials (2016) y coeditora de Pretérito Indefinido, Afectos Políticos, Mapas de la transición, Trabajos de la memoria y Pensar la democracia. https:/ /segapblog.wordpress.com/

\section{COMO CITAR ESTE ARTículO, DE ACUERDO CON LAS NORMAS DE LA REVISTA:}

MACÓN, Cecilia. "La simulación como performance afectiva en los orígenes del feminismo". Revista Estudios Feministas, Florianópolis, v. 28, n. 2, e72434, 2020.

\section{CONTRIBUCIÓN DE AUTORÍA}

No se aplica.

\section{FINANCIACIÓN}

UBACyT 2018-2020. Universidad de Buenos Aires

\section{CONSENTIMIENTO DE USO DE IMAGEN}

Archivo General de la Nación Argentina

\section{APROBACIÓN DE COMITÉ DE ÉTICA EN INVESTIGACIÓN}

No se aplica.

\section{CONFLICTO DE INTERESES}

No se aplica.

\section{LICENCIA DE USO}

Este artículo está licenciado bajo la Licencia Creative Commons CC-BY Internacional. Con esta licencia se puede compartir, adaptar, crear material para cualquier objetivo, siempre que se le atribuya la autoría.

\section{HISTORIAL}

